\title{
Electricity Logistics Storage Integration System Research
}

\author{
Bingjian Li*, Bingwu Liu, Juntao Li \\ School of Information, Beijing Wuzi University, Beijing, China \\ Email: ${ }^{* 1007834536 @ q q . c o m}$
}

Received 28 January 2015; accepted 22 February 2015; published 27 February 2015

Copyright (C) 2015 by authors and Scientific Research Publishing Inc.

This work is licensed under the Creative Commons Attribution International License (CC BY). http://creativecommons.org/licenses/by/4.0/

(c) (i) Open Access

\begin{abstract}
With the booming of e-commerce business and high requirement of customer, the operation mode of e-commerce distribution center is changing. Automation equipment cannot be utilized fully due to the nature fact of electricity business, which can be described as small batch and high frequency. In this article, we put forward a new electronic commerce operation mode which is named as ecommerce logistics distribution center storage integration system. This system is based on the work of analyzing the shortcomings of current electricity distribution center business model and drawing lessons from foreign advanced model. This model not only reduces human labor, but also uses labor resources reasonably. By focusing on the end link differentiation, we make this mode keep the same pace with business mode reform.
\end{abstract}

\section{Keywords}

Electronic Commerce, Distribution Center, Store Points Integration System

\section{Introduction}

In recent years, logistics technology in china has made great progress. We are catching up with the international logistic development trend. Different from the traditional logistics system, electricity commerce features varieties of orders, small batch and high frequency. These characters make electricity distribution center construction very different from traditional logistics system. The application of the automation equipment and overall solution has to adapt to electricity commerce development.

We research distribution center of B2C business enterprises and other small and medium-sized e-commerce company in our country, and we find out human labor is the most widely used operation mode in storage and pick process. However, goods inbound and outbound always feature short cycle, many varieties, little batch and

${ }^{*}$ Corresponding author.

How to cite this paper: Li, B.J., Liu, B.W. and Li, J.T. (2015) Electricity Logistics Storage Integration System Research. iBusiness, 7, 10-17. http://dx.doi.org/10.4236/ib.2015.71002 
high frequency, which make electricity storage and pick mode different from the traditional model.

Currently, electronic commerce in our country mainly depends on human labor operation, which is of high cost and low efficiency. It can't meet the demand of quick response service. Electricity commerce distribution center must be different from traditional logistics system to adapt to quick response demand of the quickly changing market. Automation equipment and the overall solution have to be adapted to the development of electricity industry characteristics. KIVA, from Amazon, is a very outstanding automation equipment which gives us an excellent example for e-commerce distribution operation mode construction in our country. E-commerce operations need to be supported by flexible and efficient logistics system. In order to utilize limited resources to critical area of electronic commerce, integrated logistics distribution center arises at the historic moment [1]-[4].

This mode is suitable for short cycle and small batches operation. This mode breaks the traditional "people to goods" type by creating "goods to people" picking model, which improves distribution center operation efficiency and customer response speed. Therefore, future electricity distribution center storage system should focus on this innovation system.

\section{Storage Integration System}

\subsection{Store the Concept of Integration System}

Store points integration system as a kind of new processing system, the electricity producers have incomparable advantages for traditional logistics distribution center business processing system. Such as high automation, high efficiency, customer order response ability, etc. But as a new mode, there is no official definition of a more exact. Storage points of this paper refers to the integration system used in the electronic commerce distribution center to optimize the working flow of distribution center based on mobile racking and intelligent warehouse robot's new operating system. The system integrating inventory, picking, storage, dispatch, and break the traditional storage partition mode. The main characteristics of the storage points integrated system is to break the original warehouse sorting each partition operation mode, take a new mode of the operation of warehouse sorting and the area and equipment.

\subsection{The Principle of Storage Integration Systems}

Traditional logistics center need to configure a large number of staff to handle the order, staff need to labyrinth in the shelves and select among the tens of thousands of kinds of goods after receiving a customer order, then package delivery to customers. The problem is the artificial labor intensity is too large, and low efficiency, error rate is also high. The bottleneck problem in the customer experience supreme electricity industry is amplified to several times. Unlike mode of people to goods picking, based on the points of integration system of e-commerce distribution center storage operation pattern, broke the traditional storage partition mode, and take the new operation mode of automation and artificial combination reasonably.

Integration system operation mode all use mobile automatic warehouse robot assisted shelves and chosen in warehousing and storage, make warehousing and chosen integrated, adopt the "goods movement people still" mode. According to the instructions, warehouse robot search for shelves automatically, generation of handling path automatically, sorting and selection tasks automatically until finish the whole inventory in the intersections. Operators at node racks and waiting for the arrival and complete the shelves inside the goods picking, picking action on the way of the adopt button is the beginning and end. And all these activities scheduling depends on strong background warehouse management system and innovative landmark code identification. The advantages of this model is that the large amount of moving, moving in the standardized operation are depended to the automated warehouse robot, and make the manpower to focus on the end of the electricity industry unique individuation, differentiation of the picking and link.

This mode not only improves the working efficiency, but also saves labor resources, make the distribution center operation mode in the direction of the more human development, at the same time, in the transition towards automation by constantly artificially, adopting this model not only reduce the strength of artificial operation, but also the use of labor resources reasonable, focus on the differentiation of their end link, with the pace of reform in line transition mode. Its disadvantage is that are still in labor resources in today's most parts, make the investment is too big that adopts the model, therefore, the model does not apply to the electric business enterprise in the initial of the middle and small. 


\subsection{The Operation Mode of Reservoir Points Integration System}

As an important link in the process of e-commerce, logistics take the physical distribution service on between merchants and customers, efficient logistic system for e-commerce enterprises plays a vital role to improve service, reduce costs, enhance competitiveness. As an e-commerce business more varieties, high frequency, small batch, the characteristics of e-commerce logistics gradually has high flexibility, high efficiency, high quality of service features. This model not only led to the rapid development of modern logistics technology and logistics equipment, but also makes the more short updating cycle of logistics mode. Compared with traditional electricity distribution center operating mode, store the operation mode of integrated systems has more advantages. The main characteristics of the storage points integrated system is to break the original warehouse sorting each partition operation mode, take the warehouse sorting and the area and equipment of a new mode of operation.

The model uses mobile automatic warehouse robot assisted selection in the chosen stage, make warehousing and picking integrated, its advantage is to move large amounts of standardized, handling operation to the automated warehouse robot, and focused human on the ends of individuation, differentiation and the selection of points on link, which not only improves the working efficiency, but also reduce the labor, and made the distribution center work towards the direction of more human, at the same time, in the transition towards automation by artificial constantly, adopting this model not only reduce the strength of artificial operation, but also the reasonable use of labor resources, focus on the differentiation of the ends link, makes the transition mode with the pace of reform in line. Its disadvantage is that in today's parts are still in labor resources, mainly makes the investment is too big to adopts the model, therefore, the model does not apply to electric business enterprise in the initial of the middle and small.

Semi-automatic chosen based on storage integration systems, is a kind of brand-new mode. The model makes the classic portrayed in the science fiction into reality. That the thousands of robot consciously corridor in the shuttle in the factory. The system has redefined the goods storage and distribution pattern of the goods stored in mobile shelves. When orders need to deal with computer control system of position to where goods shelves, then order one or a set of batteries orange robot along the ground encoded network route to the corresponding shelf below the top shelf and put it to the order processing personnel's work position. After staff get the goods from the shelves, the robot will transported it back to the original store. Logistics center stores and distribution of goods not make workers busy scene in this advanced warehousing, replaced by a group of robots under computer control in an orderly way across it and its carrying shelves. Compared with the traditional warehousing and distribution system, the system can be one or two times higher order processing efficiency, this advantage for highly dependent on warehousing and distribution of large-scale retail and e-commerce site has strong attraction.

Before the picking operations, the goods have been stored in the logistics center of a specific position, effective storage management can make the order picking more rapid and accurate. Reservoir management needs support with certain reservoir storage strategy, storing storage strategy is mainly refers to store a set of assignment principle, there are five main storage strategy, they are stored, random storage, classification, storage, classification, storage and shared storage. As shown in Figure 1 is frame integration systems and storage method.

\section{Verification and Analysis}

E-commerce logistics storage integration systems make integrating storage together, using new type of AGV

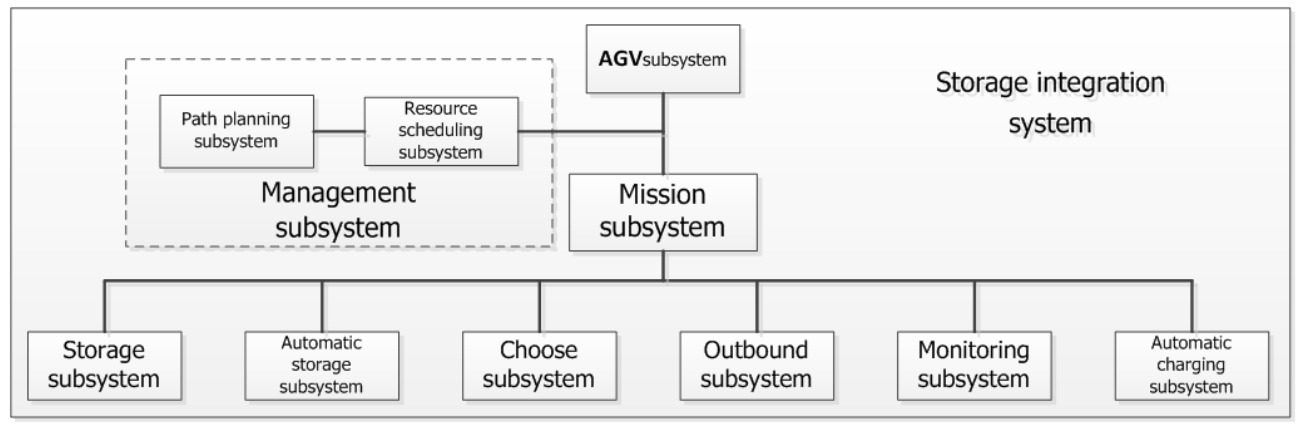

Figure 1. Store integrated system and method. 
storage and chosen to walk and handling operations orderly, its operation mode broke traditional electric business operation manual traverse every reservoir for storage assignment model chosen, become a kind of new type of e-commerce distribution center operation automation model. Using computer simulation technology to the automatic logistics system simulation can not only build physical test simulation system of huge investment, reduce the cost of investment, but also through the analysis of the simulation technology for precise calculation and verification, and improve the feasibility of the system. The validated simulation based on different logistics distribution strategy in order to find the optimal solution of the allocation of resources. After the simulation run, according to the statistics report generated simulation, show the logistics equipment utilization rate, and model.

In this paper, based on the actual investigation data and analysis, under the premise of reasonable assumptions for some key links and the parameter, for a specific situation as the research object, based on the integration systems and storage to research .The statistics are based on an electric business platform $3 \mathrm{c}$ goods actual month sales data statistics, category that includes more than $90 \%$ of the 3 c product rules effectively. Goods mainly divided into the power supply, mobile phones, laptops and cameras four broad categories, a total of $812 \mathrm{SKU}$. Known this statistical electric business platform with the target electric business platform 3 c category market share proportion for 25:38:1, which estimate the total sales target platform, and each product sales of gauge, then analyzed for each category of sales data segment, in order to realize the whole ABC classification rules. At the same time, estimate the target platform single common areas warehouse in all kinds of parameters according to the proportion of market share and target platform national total area points warehouse number.

By statistical data characteristics, the ABC classification of the data has obvious differences. 812 SKU sales 586769 a month, set 12 SKU before sales as class A, the rest of the former 188 SKU as class B, the remaining 612 SKU for class $C$. The electric business platform 3 c month sales detailed statistics shown in Table 1.

Estimate the $A B C$ class separately by the above all kinds of commodity sales proportion, class A: 1:1:0:0; Class B: 2:1:4 emit. 5; Class C: 1.5:5.5:1:2. At the same time can be calculated proportion of the total ABC class A: B: C: 2.2 4:1. Target platform has six large area across the country, therefore, a warehouse in sales of about 150,000 on average. Assume that the target warehouse storage days to 6 days, then its stock is 30,000, capacity of calculated on the stock of 1.2 times, so the storage capacity is about 36,000 pieces. According to the above calculation ratio can be divided into three categories, A class of 11,000; Class B for 20,000; Class C for 5000. Three types of goods storage capacity are shown in Figure 2.

Actual research platform and target platform forms are different, but because the forces of the market economy, the market of customer are similar groups, customer loyalty in the same commodities, therefore each merchandise category sales ratio is roughly same, continue to use the above four types of commodity sales proportion in the ABC goods to calculate the target platform of all kinds of goods storage capacity of 6 days, specifically shown in Table 2.

Every day from 6 days of storage capacity calculated amount of in-out warehouse, loading and unloading quantity about 6000 every day. According to the characteristics of the 3 c goods orders, 3 c class more for highend luxury goods, the average single parts, namely the processing about 6000 every day. For the largest amount calculated at 1.5 times, loading and unloading amount to 9000 , the largest. The planning of the distribution center logistics capability is as shown in Table 3.

This paper uses the Tecnomatix Plant Simulation 9 logistics system Simulation software. Tecnomatix Plant Simulation (eM-Plant), is provided by Siemens company Logistics process Simulation and optimization software, its predecessor was SIMPLE++, is dedicated to the discrete system modeling and Simulation analysis, and is used to implement about the production, logistics and engineering Simulation software (Simulation in Produc-

Table 1. An electric business platform 3 c month sales statistics table.

\begin{tabular}{cccc}
\hline An electric business platform & Class A & Class B & Class C \\
\hline Power supply & 91,434 & 70,298 & 12,187 \\
Mobile phone & 96,219 & 227,407 & 35,277 \\
Computer & 0 & 3679 & 8054 \\
Camera & 0 & 16,527 & 15,687 \\
Combined & 187,653 & 317,911 & 81,205 \\
\hline
\end{tabular}


Table 2. Target electric business platform ABC storage of goods.

\begin{tabular}{|c|c|c|c|c|}
\hline Target electric business platform & Class A & Class B & Class $\mathrm{C}$ & Combined \\
\hline Power supply & 5500 & 4393 & 750 & 10,643 \\
\hline Mobile phone & 5500 & 14,335 & 2750 & 22,585 \\
\hline Computer & 0 & 231 & 500 & 731 \\
\hline Camera & 0 & 1041 & 1000 & 2041 \\
\hline Combined & 11,000 & 20,000 & 5000 & 36,000 \\
\hline
\end{tabular}

Table 3. Target distribution center logistics capability clock.

\begin{tabular}{cc} 
Project & Logistics capability \\
Storage capacity & More than 36,000 \\
Average daily volume for ins and outs of & 6000 \\
Loading and unloading quantity biggest & 9000 \\
Substandard goods species & More than 812 \\
\hline Choose time & Storage capacity \\
\hline
\end{tabular}

Figure 2. Three kinds of goods storage capacity chart.

tion, Logistics and Engineering \& its implementation in $\mathrm{c}^{++}$).

We can see from the storage efficiency of bar chart, four mouth warehouse receipts respectively shelves number 62, 60, 60, 45, the result is consistent with the expected distribution.

From the results put in storage, 5 hours 20 minutes to the distribution center by the empty warehouse into a full warehouse (Figure 3). It can meet the requirements from the efficiency. And warehousing line chart of basic for an upward sloping straight line, this is decided by the design of the incoming order, indicate that the basic stable storage process.

In choose outbound links, after many simulation experiments, selecting the typical experimental results to analysis. After 1 hour and 48 minutes and 50 seconds. Below for the period of time each has chosen mouth bar charts and selection efficiency curve. This simulation is the premise, the hypothesis of perfect goods according to the ABC classification of outbound probability to generate random outbound order 400, after system treatment to generate the picking list, carrying shelves 200 times back and forth, and an average of one picking rack contains two orders.

We can see from the sorting efficiency bar chart, the four chosen mouth to complete orders shelves number are 10, because each order picking orders for 10 shelves, each chose to complete orders for 100 , the result is consistent with the expected distribution.

Efficiency line chart we can see that will be chosen from the time when you arrive at 35 minutes, picking total quantity tends level remains unchanged, that is chosen for about 35 minutes, 35 minutes to complete the 400 order picking task (Figure 4).

From the simulation results (Figure 5), 1 hour and 48 minutes can finish 400 order picking, packaging, auto- 


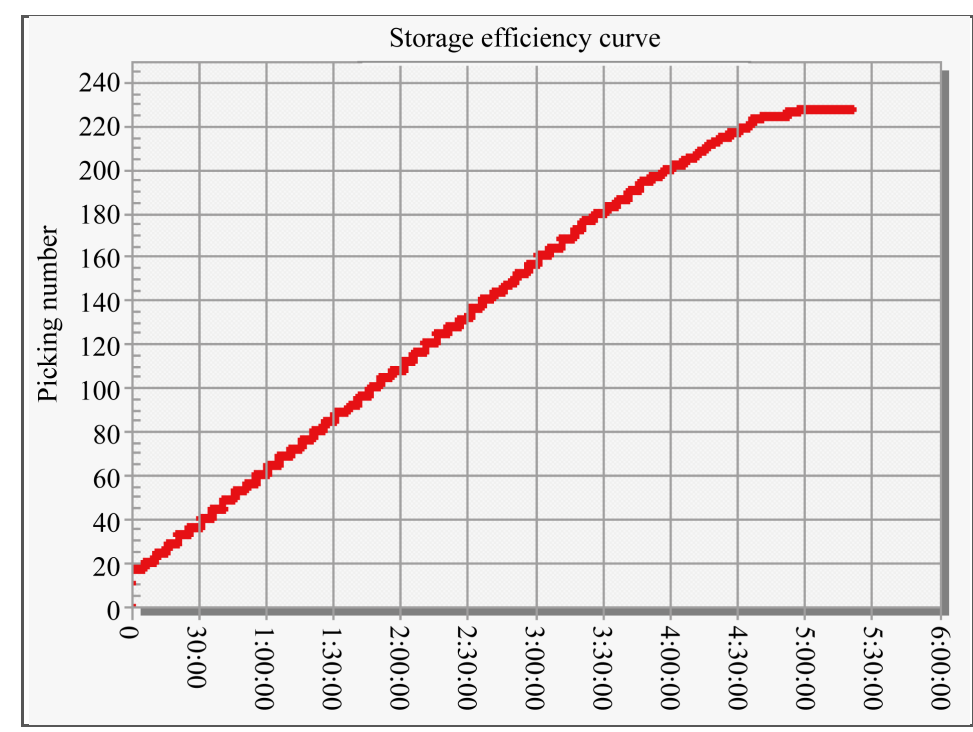

Figure 3. Storage efficiency line chart.

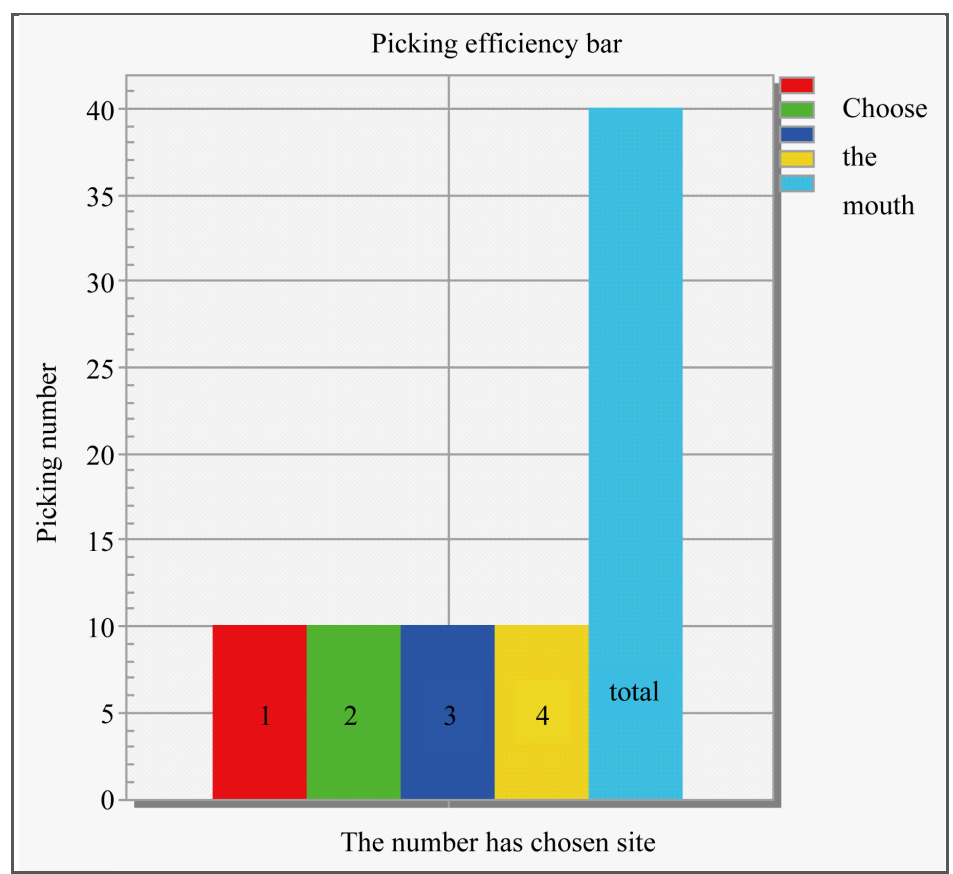

Figure 4. The picking efficiency bar charts.

matic sorting, into the shuttle car stereo libraries and shuttle car stereo repository for outbound whole process. The picking time is about 35 minutes, for the shuttle car stereo time (including packaging) and automatic sorting time is about 35 minutes, shuttle car stereo library for outbound time approximately 42 minutes, basic can meet the requirements from the efficiency. At the same time the picking line chart (effective) for an upward sloping straight line, that in the case of random order allocation, the selection process was basically stable.

Now divide the e-commerce store integrated system model and the traditional manual mode in the chosen segment were analyzed. 400 orders in the simulation model of data, for example, the content in Table 4 for the two modes have chosen link various points link operation name and the time required.

As you can see from Table 4, storage integration systems and the picking link artificial selection model has certain advantage in efficiency. 


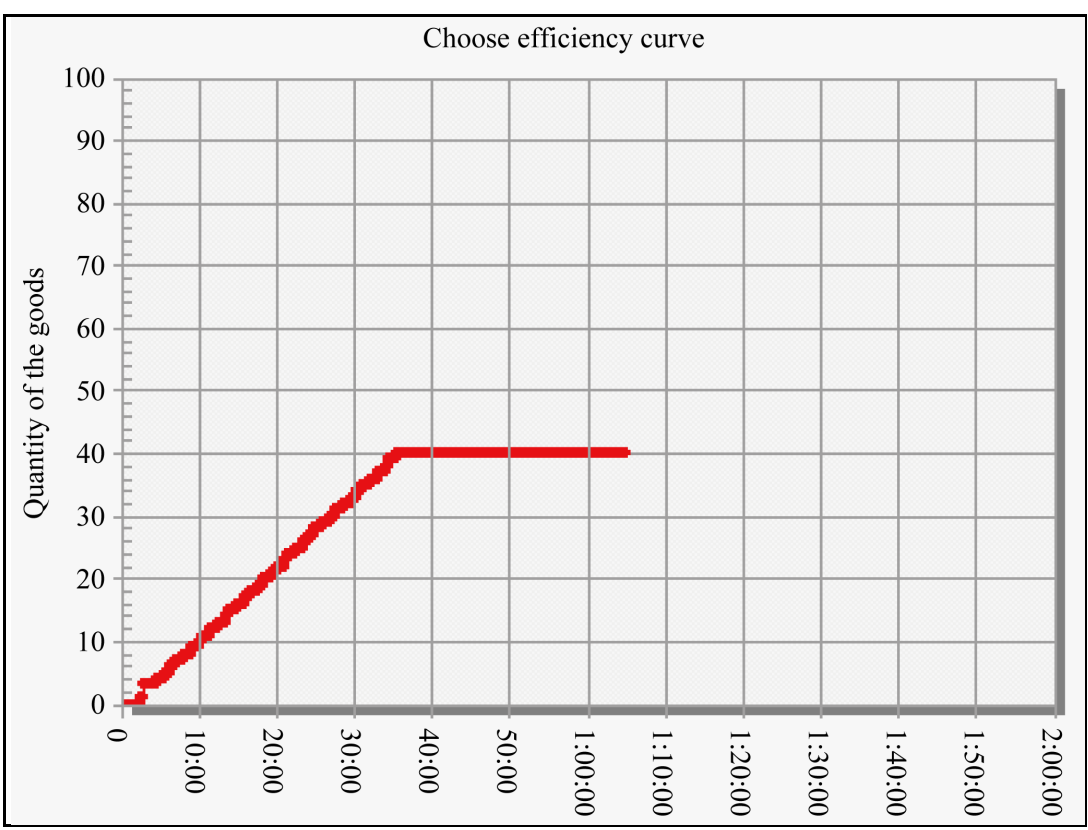

Figure 5. Choose efficiency line chart.

Table 4. Two modes have chosen contrast table.

\begin{tabular}{ccc}
\hline & Store points integration system chosen mode & The traditional manual picking mode \\
\hline Order for goods shelves & $\begin{array}{c}\text { Preparation, will be chosen in a place, it took } \\
\text { about } 2000 \mathrm{~s}\end{array}$ & $\begin{array}{c}\text { After picking points on preparation, require } \\
\text { two points, it took about } 2000 \mathrm{~s}\end{array}$ \\
Picking link & It took about $35 \mathrm{~min}$ & It took about $41 \mathrm{~min}$ \\
Cargo link & $/$ & It took about 10 min \\
Comprehensive & Choose always takes about 35 min & Choose always takes about 51 min
\end{tabular}

\section{Conclusion}

Logistics center operation mode is developing along with development of electronic commerce. Advanced automation device is gradually replacing the human labor. Informational system is becoming an important symbol for a modern distribution center. New operation mode is emerging every day. For example, RFID picking, electronic tags picking and voice picking are replacing human picking. Technology is bringing convenience to every operation link. But neither equipment update nor operation mode update can change the situation that employees walk around the picking area several times every day just to pick out dozens of single commodity. Automation is mostly reflected in final sorting link. Picking and storing various products are always the operation bottleneck in electricity distribution center. How to fundamentally solve these problems and realize storage/picking process automation is a difficult problem. The integrated electronic business logistics storage and picking system can effectively solve this problem. This system will give specific picking action tasks to human; other searches and carry tasks are given to AGV. This is a very innovational system for distribution center operation.

\section{Acknowledgements}

This research was supported by the Beijing key intelligent logistics system laboratory.

\section{References}

[1] Hang, X.H. and Chen, Q.H. (2012) Several Kinds of Picking Mode and Electricity Logistics Case. Information and Computers, 2, 30-34. 
[2] Wang, H.W. and GAO, L.L. (2011) B to C E-Commerce Logistics Distribution Center Operational Efficiency Evaluation. Journal of Commercial Age, 8, 38-39.

[3] Li, S.Z. (2011) Way of Picking, Storage Strategy and Path Strategy Synergy Study. Industrial Engineering, 14, 37-43.

[4] Wang, X.N. (2012) E-Commerce Logistics Management. Peking University Press, Beijing. 
Scientific Research Publishing (SCIRP) is one of the largest Open Access journal publishers. It is currently publishing more than 200 open access, online, peer-reviewed journals covering a wide range of academic disciplines. SCIRP serves the worldwide academic communities and contributes to the progress and application of science with its publication.

Other selected journals from SCIRP are listed as below. Submit your manuscript to us via either submit@scirp.org or Online Submission Portal.
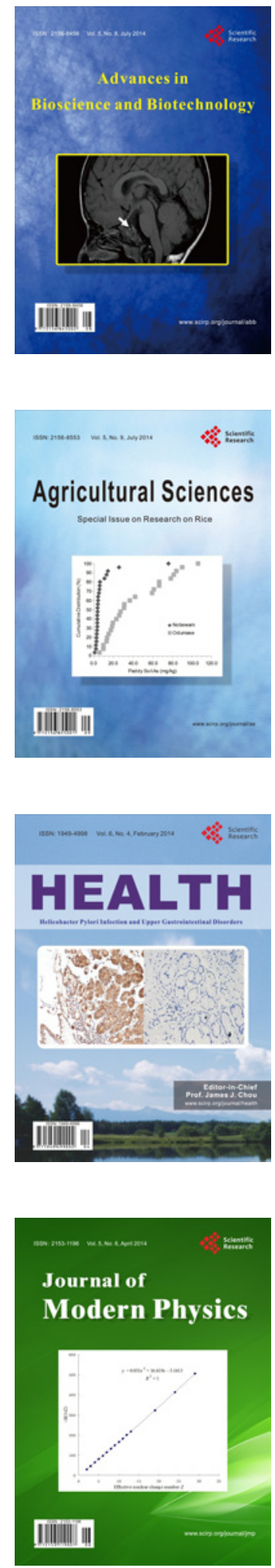
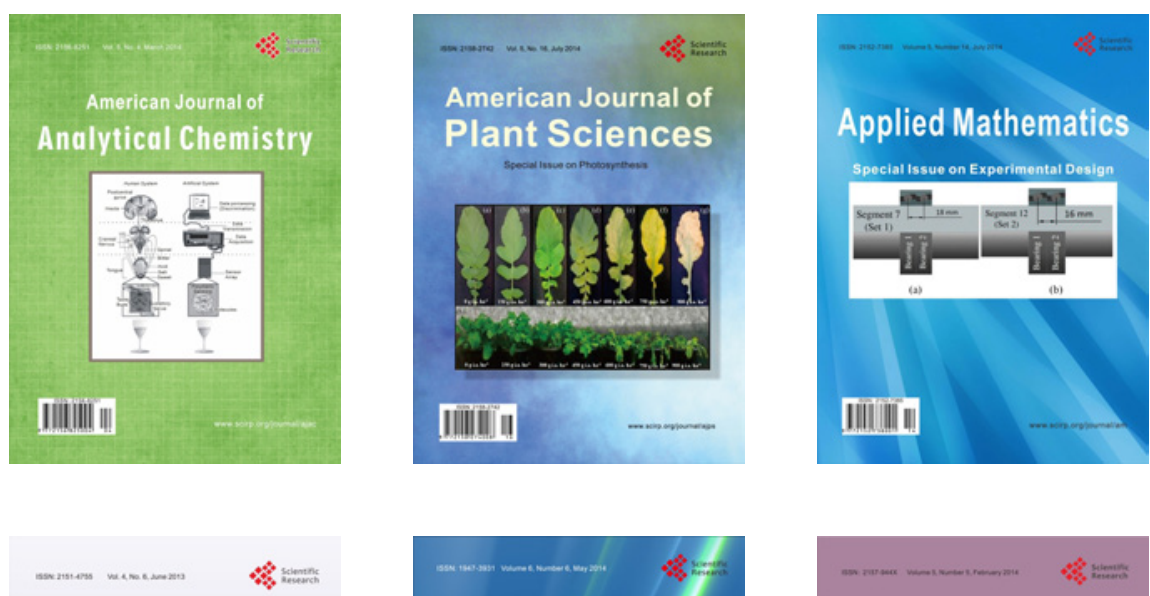

Creative Education
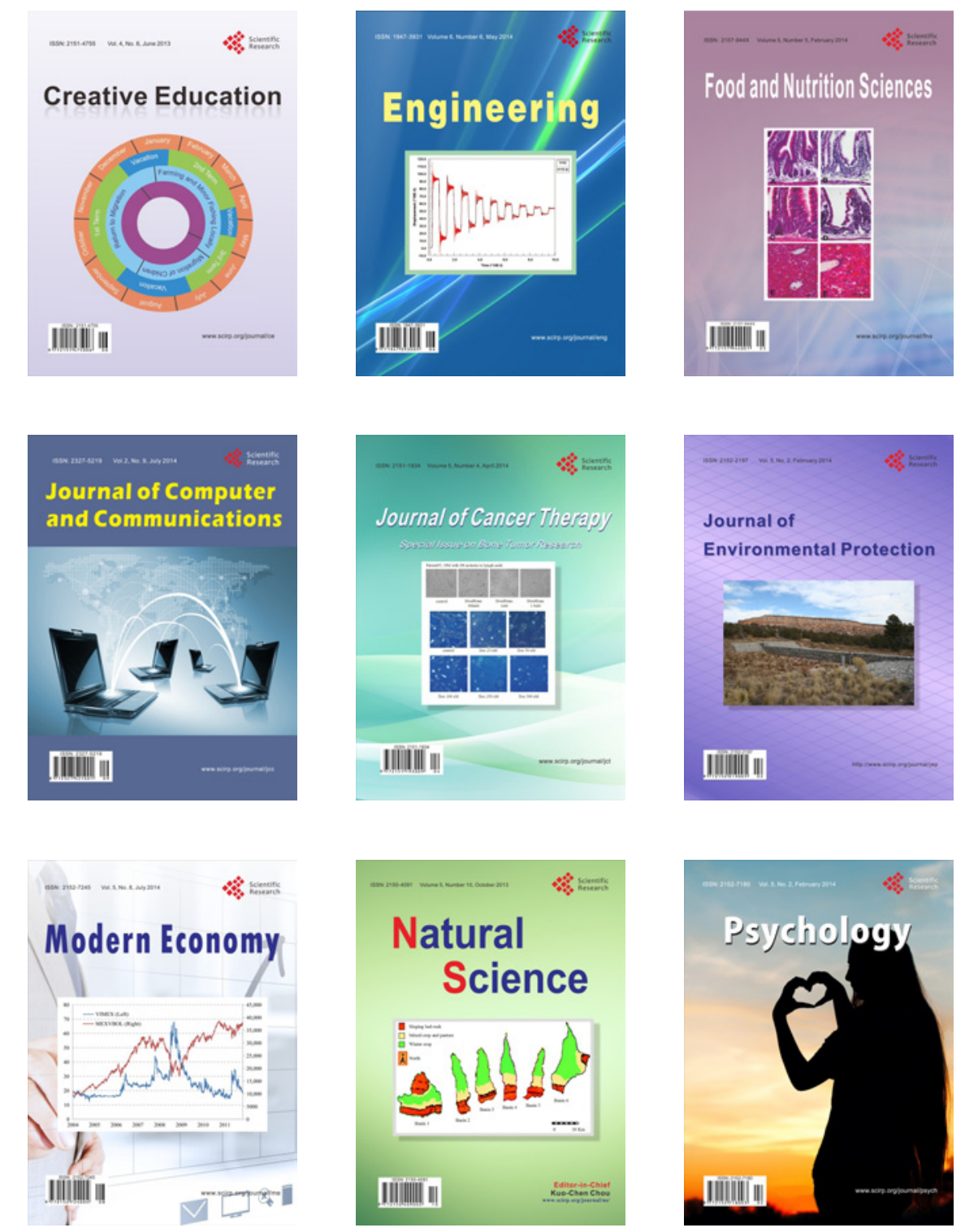